"The submitted manuscript has been authorized by a contractor of the U.S. Government under contract No. DE-ACO596OR22464. Accordingly, the U.S. Government retains a nonexclusive, royalty-free license to publish or reproduce the published form of this contribution, or allow others to do so, for U.S. Government purposes."

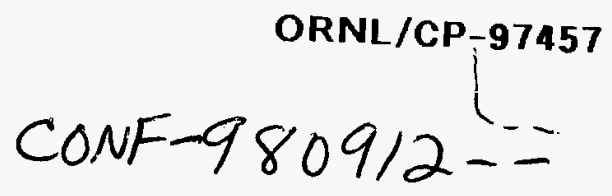

\title{
Verification of Creep Performance of a Ceramic Gas Turbine Blade
}

\author{
H. T. Lin, P. F. Becher, M. K. Ferber, and V. Parthasarathy*
Metals and Ceramics Division, Oak Ridge National Laboratory, Oak Ridge, TN 37831-6068, fff \\ *Solar Turbines Incorporated, San Diego, CA 92101
}

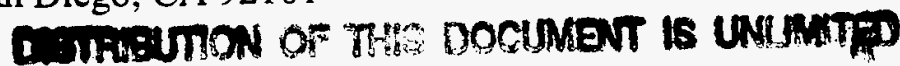

Keywords: Creep, Silicon Nitride, Gas Turbine Blade, Ceramic Component Verification RE CEIVED

MAY O 61998

\begin{abstract}
Tensile creep tests were carried out on a Norton NT164 silicon nitride ceramic turbine blade containing 4 wt. \% $\mathrm{Y}_{2} \mathrm{O}_{3}$ sintering additive at $1370^{\circ} \mathrm{C}$ in air under selected stress levels. The objective of this study was to measure the creep properties of test specimens extracted from a complex shaped ceramic gas turbine blade to verify the response of actual components. The creep results indicated that specimens from both the airfoil and dovetail sections exhibited creep rates that were about 4 to 100 times higher than those obtained from both the buttonhead and dogbone creep specimens machined from the developmental billets fabricated with the same composition and processing procedures. Electron microscopy analyses suggested that high creep rates and short lifetimes observed in specimens extracted from the turbine blade resulted from a higher glassy phase(s) content and smaller number density of elongated grain microstructure.
\end{abstract}

\section{Introduction}

Silicon nitride ceramics with an in-situ reinforced elongated microstructure have been the primary candidates for both advanced automotive and land-base gas turbine engine applications due to their superior thermomechnical properties (e.g., strength, fracture toughness, and fatigue and creep resistance) [1-3]. Various ceramic components, e.g., turbine blades, nozzles, and turbo compressors, have been mass produced for actual component application or field tests. It should be realized that the progression in the manufacturing technology from small batches of simple shaped ceramic pieces to large scale production of complex shaped components is evolutionary. Often various processing steps, even material compositions, may be modified to produce materials with consistent mechanical properties when scaling up production. A key issue in the development of ceramic components is the ability to document the mechanical properties of complex shaped components and determine if these are comparable to those obtained from simple test coupons utilized in the development of ceramic materials. One, therefore, needs to determine whether the long-term mechanical reliability and lifetime of ceramic components are comparable to those obtained from developmental materials. In addition, lifetime prediction of ceramic components generally employs the database generated from developmental materials, which may not be applicable to the case of ceramic components. At present there is no database available for ceramic components for end users and advanced design capability. This study was carried out to measure the creep properties of test specimens extracted from complex shaped ceramic gas turbine blades to verify the response of actual components subjected to applied tensile stresses at elevated temperatures in air. The creep results are compared with those obtained from developmental billets. The processes limiting for reliability and lifetime of ceramic gas turbine components will be discussed.

\section{Experimental Procedures}

The silicon nitride ceramic (designated as Norton NT164) turbine blade evaluated in the present study was fabricated via a slip-cast plus hot isostatically pressing (HIP) processes with a $4 \mathrm{wt} \% \mathrm{Y}_{2} \mathrm{O}_{3}$ sintering additive (manufactured by SaintGobain/Norton Industrial Ceramics Corporation, Northboro, MA). X-ray analyses indicated the presence of minor phases of $\gamma-\mathrm{Y}_{2} \mathrm{Si}_{2} \mathrm{O}_{7}$ and $\mathrm{Si}_{2} \mathrm{~N}_{2} \mathrm{O}$ in the as-received $\mathrm{NT} 164$ turbine blade, which were similar to those observed in the developmental billets. However, the $\mathrm{X}$-ray analyses revealed that the turbine blade contained smaller volume fractions of $\mathrm{Si}_{2} \mathrm{~N}_{2} \mathrm{O}$ and $\gamma-\mathrm{Y}_{2} \mathrm{Si}_{2} \mathrm{O}_{7}$ than those present in the developmental billets. In addition, the electron microscopy analyses showed that turbine blade exhibited a microstructure that contained a smaller number density of large elongated grains plus a finer matrix grain size as compared with the microstructure of the developmental materials.

The small dog-bone type tensile creep specimens, similar to NIST SR30 [4], were extracted from the as-received turbine blades. The complexity of the turbine blade shape and profile made it difficult to extract the tensile creep specimens from 


\section{DISCLAMER}

This report was prepared as an account of work sponsored by an agency of the United States Government. Neither the United States Government nor any agency thereof, nor any of their employees, makes any warranty, express or implied, or assumes any legal liability or responsibility for the accuracy, completeness, or usefulness of any information, apparatus, product, or process disclosed, or represents that its use would not infringe privately owned rights. Reference herein to any specific commercial product, process, or service by trade name, trademark, manufacturer, or otherwise does not necessarily constitute or imply its endorsement, recommendation, or favoring by the United States Government or any agency thereof. The views and opinions of authors expressed herein do not necessarily state or reflect those of the United States Government or any agency thereof. 
the blades. A coordinate measurement machine was, consequently, used to precisely outine the profile of the complexshaped turbine blade to allow one to efficiently extract test specimens. The location of each tensile specimen in the turbine blade was also carefully tracked to assess the uniformity of the creep properties.

Tensile creep tests were carried out in a high temperature creep frame with a pneumatic-type loading system. The tensile stress was applied to creep specimens via $\mathrm{SiC}$ pins and pull rods. The applied stress was continuously monitored and controlled using a personal computer with a LabView application program (National Instruments, Austin, TX) . The creep displacement was measured by an optical-based laser extensometer equipped with a water-cooled laser path shield. The resolution of laser extensometer at test temperature is $\pm 0.5 \mu \mathrm{m}$, which is limited by the data microprocessor. The details of tensile creep test procedures can be found in Ref. [5]. After tensile creep tests, the creep damage (cavitation) features were evaluated by using both optical and scanning electron microscopy.

\section{Results and Discussion}

\section{High temperature creep response}

Figure 1 shows the creep rate and lifetime results of Norton HIP NT164 silicon nitride turbine blade at $1370^{\circ} \mathrm{C}$ in air. The creep data obtained from both buttonhead and dogbone (NIST SR51 type [4]) specimens. which were all machined from the same developmental billets, are included for comparison $[5,6]$. Note that previously published results suggest that the use of small dogbone specimens yields creep results (both creep rates and lifetimes) comparable with those obtained from large buttonhead specimens using a super grip system. Thus, changes in size and geometry of test specimens did not influence the creep results for tests on the exact same material.

However, the present creep results indicated that specimens from the airfoil section exhibited the highest creep rates and shortest lifetimes as compared with those obtained for specimens machined from either (1) the dovetail section of a turbine blade or (2) the developmental billets (Fig. 1). Note that the airfoil specimens, which were tested at stresses $>125 \mathrm{MPa}$, failed during the primary creep regime with shor lifetimes $<1 \mathrm{~h}$. At the same time, the specimens extracted from the dovetail section exhibited creep rates that were about five to ten times higher than those for specimens from the developmental billets (Fig. 1a). Interestingly, specimens from the dovetail section exhibited creep lifetimes that were comparable to those machined from developmental billets. There was one exception: a specimen tested at $175 \mathrm{MPa}$ exhibited a lifetime of $\sim 4$ h (Fig. Ib).

The slopes of creep rate versus stress curves, stress exponents (n), of specimens from both airfoil and dovetail sections were similar $(n-10)$. The exponents of turbine blade specimens were much higher than the one $(n-1.5)$ obtained for specimens machined from developmental billets under the same stress levels $\leq 175 \mathrm{MPa}$ (Fig. la), but at stresses $>200 \mathrm{MPa}$ it
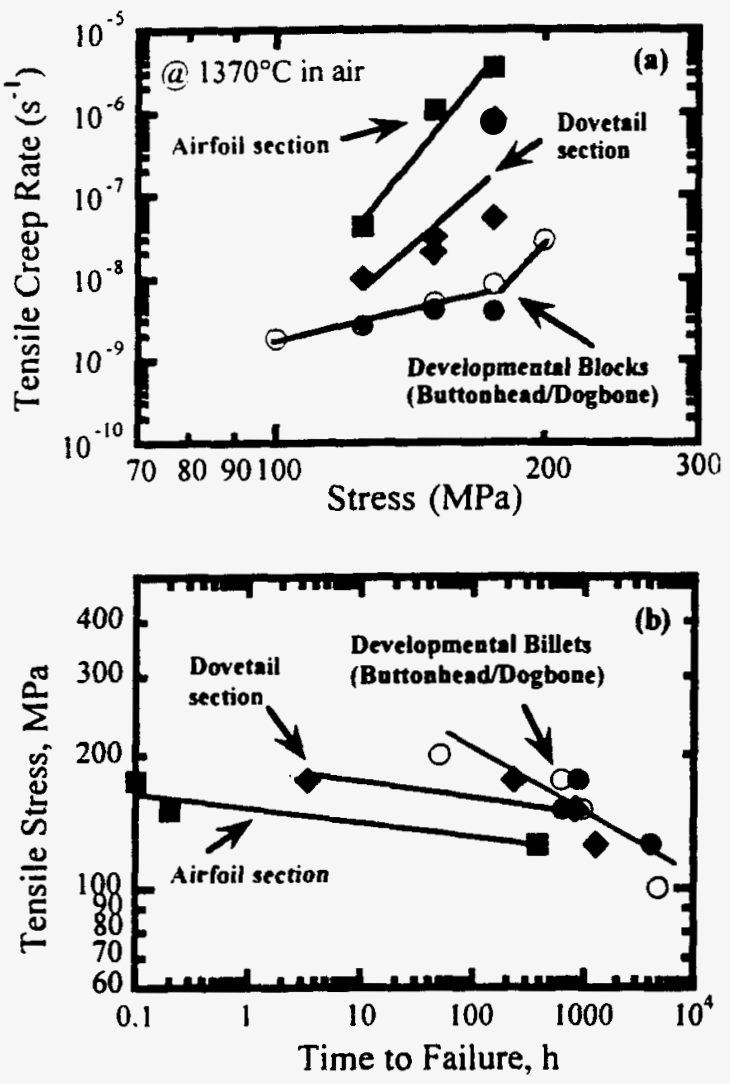

Figure 1. Creep rate and lifetime results of Norton nitride materials NT164 silicon nitride turbine blade and developmental billets at $1370^{\circ} \mathrm{C}$ in air. appeared slope might increase for the developmental material. The high $n$ values obtained for silicon nitride materials and ceramics with liquid phase(s) are, in general, attributed to enhanced creep cavitation $[7,8]$.

\section{Creep damage characterization}

After high temperature creep testing, the original fracture surfaces were obscured due to surface oxidation when these surfaces were exposed to the high-temperature environment during the cool down period. Therefore, secondary fracture surfaces in the gage section were generated at room temperature to examine the extent of creep damage. Note that the secondary fracture surfaces created at room temperature were perpendicular to the tensile stress direction. Figure 2 shows the SEM photomicrographs of specimens machined from turbine blade (Fig. 2a) and developmental billets (Fig. 2b), which were tested at $1370^{\circ} \mathrm{C} / 175 \mathrm{MPa}$ in air. SEM observations indicated that, in general, creep cavitation of NTI64 silicon nitride occurred in multiple grain junctions within fine grained regions and along grain boundaries. The specimen from developmental billets exhibited very few lenticular-shaped cavities at large elongated grain boundaries (Fig. 2a), which was 
consistent with those reported from the same NT164 silicon nitride material by Ferber et al. [6]. The very limited number of cavities was attributed earlier to either the absence of or a very thin glassy film $(\ll<1 \mathrm{~nm})$ along large elongated grain boundaries [6]. Cavities were also found in the multigrain junctions within the fine grained regions of developmental specimens.

SEM examinations of the present study indicated that a higher concentration of creep cavities was found at large elongated grain boundaries of turbine blade specimens (Fig. 2b) as compared with those observed in specimens machined from developmental billets (Fig. 2a). These creep cavities are mostly associated with (1) a relatively thick intergranular glassy phase and (2) interfaces approximately normal to the tensile stress direction. Creep cavities were also found in the multigrain junctions within the fine grained regions of turbine blade specimens similar to those observed in the developmental specimens.

The secondary fracture surfaces can effectively reveal cavities along the large elongated grain junctions (Fig. 2). However, the complex fracture surface morphology prevented a detailed examination of multigrain cavities within fine grained regions. In this case, specimens of longitudinal gage section including the original high-temperature fracture surfaces were polished and plasma-etched to compare the creep cavitation feature and cavity number density.

Figure 3 shows the SEM micrographs of specimens from developmental billets (Fig. 3a) and turbine blade (Fig. 3b), tested at $1370^{\circ} \mathrm{C} / 175 \mathrm{MPa}$ in air. SEM examinations indicated that creep cavitation occurred uniformly along the gauge sections of specimens from both developmental billets and turbine blade. The developmental specimens, in general, exhibited few cavities along the elongated grain boundaries, which confirmed the SEM observations of secondary fracture surfaces (Fig. 3a). Few multigrain cavities within the fine grained regions were also found in the developmental specimens.

On the other hand. SEM observations showed that the turbine blade specimens exhibited a higher concentration of creep cavities (at least ten times) along the elongated grain boundaries than those observed in specimens machined from developmental billets (Fig. 3b). These two-grain junction cavities were mostly perpendicular to the tensile stress direction or at an angle $>50^{\circ}$ (Fig. 3). Note that no creep cavities were observed at elongated grain boundaries parallel to the tensile stress direction. Formation of full-facet cavities and/or wedge cracks due to the coalescence of creep cavities was also observed along the elongated grain boundaries in the turbine blade specimens, which were not observed in specimens machined from developmental billets. SEM observations of turbine blade specimens also showed that more creep cavities formed in multigrain junctions within fine grained regions as compared with those formed in the developmental specimens (Fig. 3). These multigrain junction cavities were found to account for $>60 \%$ of the total creep strain in the Norton NT154 silicon nitride ceramics reported in previous studies $[6,9]$.

Creep deformation in HIP silicon nitride ceramics has been generally attributed to the diffusional mechanisms of solution/precipitation, viscous flow, and grain boundary sliding $[6,9,10]$. Creep cavities formed when the creep strain can not be fully accommodated. The volume fraction of creep cavities formed was, generally, found to be proportional to the creep strain of specimens as reported in previous creep studies of Norton NT154 silicon nitride [9]. The observed higher creep rates of specimens extracted from turbine blade appeared to be due to the extensive formation of creep cavities along the elongated grain boundaries and at multigrain junctions (Figs. 2 and 3 ). The occurrence of more creep cavities along large elongated grain boundaries of turbine specimens could be probably due to the presence of relatively thick glassy phase (Fig. 2b), which could allow the solution and precipitation processes involving silicon nitride grains to occur readily, resulting in formation of a larger number of creep cavities. The smaller number density of large elongated grains coupled with the finer matrix silicon nitride grains would enhance grain boundary sliding and. hence, cavitation leading to the observed higher creep rates (Fig. 1). It was also suggested that the glass-encapsulated HIP process could allow the glass elements (e.g., $\mathrm{Ca}$. Na. B) to readily diffuse into the bulk of thin ceramic turbine blade (2-4 mm in thickness) [11]. The introduction of these glass modifier elements could substantially alter and decrease the softening point and viscosity of glassy phase(s) in the silicon nitride ceramics [12]. As a result, creep cavitation at grain boundaries and multigrain junctions would be greatly promoted. further enhancing creep deformation rates as indicated in previous studies [12,13]. The present study clearly demonstrated that the high-temperature creep properties of complex-shaped ceramic components 
may not be necessarily consistent with those observed in the developmental materials due to the differences in microstructure and content and/or chemistry of secondary phase(s). It is critical that a ceramic components database needs to be developed. in addition to the database of developmental materials. to ensure an accurate lifetime prediction results and for structural design capabilities.

\section{Summary}

Tensile creep results at $1370^{\circ} \mathrm{C}$ in air indicated that there existed a difference in creep properties between the turbine blade and developmental material of HIP NT 164 silicon nitride materials. The specimens extracted from both airfoil and dovetail sections exhibited higher creep rates and shorter lifetimes than those (both buttonhead and dogbone specimens) machined from developmental billets. The poor creep performance at $1370^{\circ} \mathrm{C}$ in air observed in specimens extracted from turbine blade was due to the extensive creep cavitation at two-grain facets and multigrain junction regions. The microstructure of turbine blade specimens exhibited a lower number density of large elongated grains and finer matrix grain size that could enhance the diffusional creep processes of viscous flow and/or grain boundary sliding. Also. the thicker grain boundary glassy film and higher glassy phase content could enhance the solution/precipitation processes, resulting in more creep cavities along two-grain facets. It is suggested that a separate database of ceramic components needs to be developed for end users and advanced structural design capabilities.

\section{Acknowledgments}

The authors thanks Drs. C. H. Hsueh and A. A. Wereszczak for reviewing the manuscript. Research sponsored by the U.S. Department of Energy, Office of Transportation Technologies, as part of the Advanced Automotive Materials Program, under Contract DE-AC05-960R22464 with Lockheed Martin Energy Research Corporation.

\section{Reference}

1. H. E. Helms, R. A. Johnson, and L. E. Groseclose, pp. 137-55 in Proceedings of the Twenty-third Automotive Technology Development Contractors' Coordination Meeting, Society of Automotive Engineers, Wartendale. PA, 1986.

2. D. Carruthers and L. Lindberg, pp. 1258-72 in Third Intemational Symposium on Ceramic Components and Materials for Engines. edited by V. J. Tennery. American Ceramic Society, Westerville, $\mathrm{OH}, 1988$.

3. H. Kawamoto, pp. 173-184 in Ceramic Transactions, Vol. 49, Manufacture of Ceramic Components. American Ceramic Society, Westervill, $\mathrm{OH}, 1995$.

4. J. D. French and S. M. Wiederhom. J. Am. Ceram. Soc., 79 [2] 550-552 (1996).

5. H. T. Lin, P. F. Becher, and M. K. Ferber, J. Am. Ceram. Soc., 77 [10] 2767-70 (1994).

6. M. K. Ferber, M. J. Jenkins. T. A. Nolan, and R. L. Yeckley, J. Am. Ceram. Soc., 77 [3] 657-65 (1994).

7. S. L. Hwang, H. T. Lin, and P. F. Becher, J. Mater. Sci., 30 (1995) 6023-6027.

8. H. T. Lin, J. O. Kiggans Jr, and T. N. Tiegs, J. Mater. Sci., 31 (1996) 6477-6483.

9. W. E. Luecke, S. M. Wiederhorn. B. J. Hockey, R. E. Krause, Jr., and G. G. Long, J. Am. Ceram. Soc., 78 [8] 2085-96 (1995).

10.M. K. Ferber and M. G. Jenkins. J. Am. Ceram. Soc., 75 [10] 2453-62 (1992).

II.R. L Yeckley, personel communication. 1998

12. I. Tanaka. G. Pezzotti. K. I. Matsushita. Y. Miyamoto, and T Okamoto, J. Am. Ceram. Soc.. 74 [10] 1886-93 (1991).

13.I. Tanaka, K. I. Igashira, T. Okamoto, K. Niihara, and R. M. Cannon, J. Am. Ceram. Soc., 78 [3] 673-79 (1995).

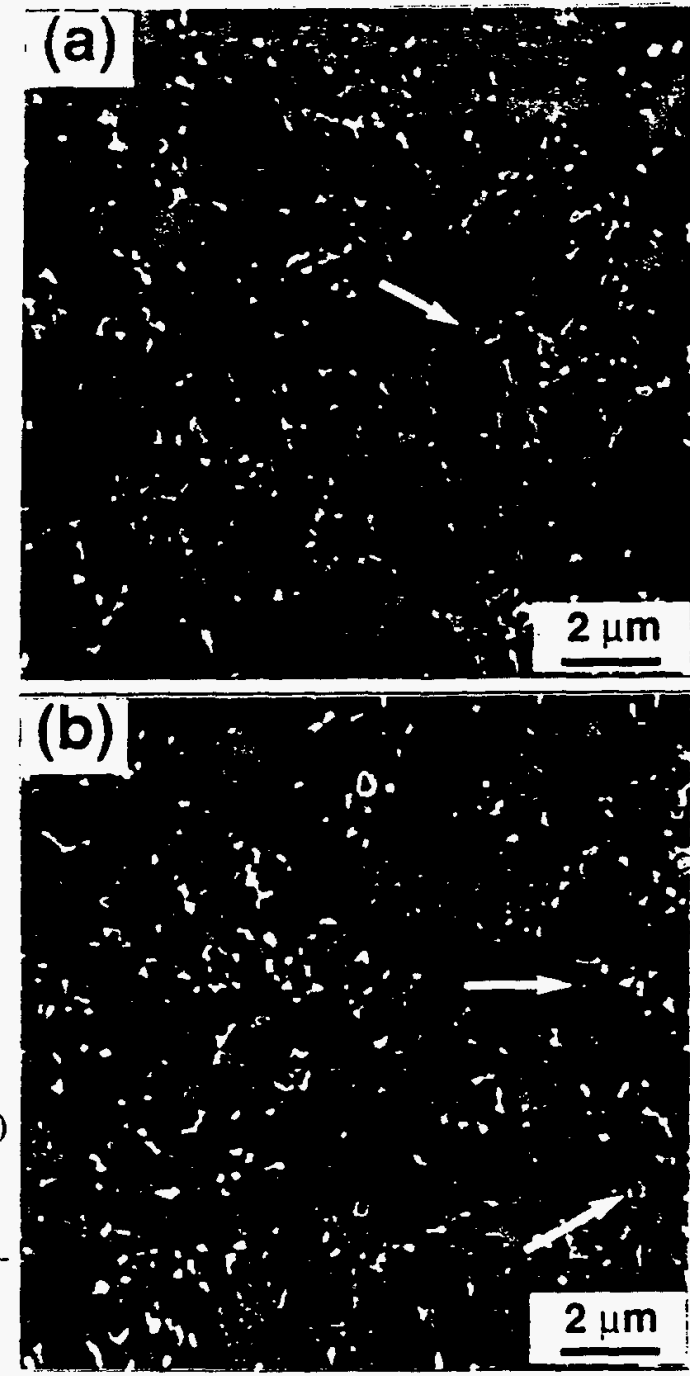

Figure 3. SEM micrographs of polished and plasma-etched crept specimens from (a) developmental and (b) turbine blade specimens tested at $1370^{\circ} \mathrm{C} / 175 \mathrm{MPa}$ in air. 


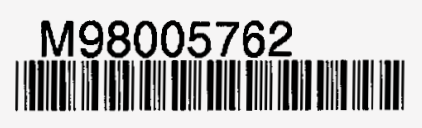

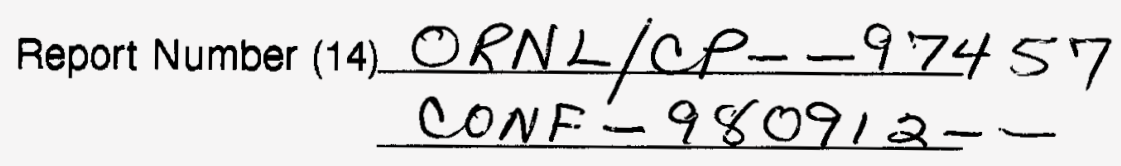

Publ. Date (11) 199803

Sponsor Code (18) DOE/EE, XF
UC Category (19)

\section{2}

DPTC QUALTYY INOPECTED 1 